\title{
Evaluating the Novel Coronavirus infection outbreak surveillance results in a state hospital: a retrospective study
}

\author{
Ezgi Dirgar ${ }^{1}$, Betül Tosun ${ }^{1}$, Soner Berşe ${ }^{2}$, Nuran Tosun ${ }^{1}$
}

1. Hasan Kalyoncu University, Faculty of Health Sciences, Nursing Department, Gaziantep, Turkey.

2. Gaziantep University, Faculty of Health Sciences, Nursing Department, Gaziantep, Turkey.

\begin{abstract}
Author details:
Ezgi Dirgar: ezgi.dirgar@hku.edu.tr, Phone: +90(342)2118080; Betül Tosun: betul.tosun@hku.edu.tr, Email: tosunbetul@gmail.com; Soner Berşe: sonerberse@gmail.com; Nuran Tosun : nuran.tosun@hku.edu.tr, Phone: +905343885574
\end{abstract}

\begin{abstract}
Background: Coronavirus disease (COVID-19) has raised the global public health concern and has been declared a pandemic by the World Health Organization.

Objectives: This study was aimed to examine the clinical course and outcomes of the patients with COVID-19 in the southeastern part of Turkey.

Methods: This retrospective study was conducted on the files of 173 patients who were diagnosed with COVID-19. The "COVID-19 Case Information Form" in the patients' medical records was used.

Results: Of the patients with COVID-19, 64.2\% were male and $16.2 \%$ had a chronic disease. Their mean age was $34.76 \pm 25.75$ years. Cough and fatigue were the most common clinical symptoms at admission with $38.7 \%$. The patients at the age of 65 and over were treated mostly in the intensive care unit, and the symptoms associated with the cardiovascular and nausea and vomiting were observed more often $(\mathrm{p}<0.05)$.

Conclusions: It was found that the majority of the patients were male and there were differences between the age groups in terms of transmission route, the clinic where they were being followed-up, some symptoms, and clinical status outcome. It is recommended that multi-center, prospective, experimental, or observational studies with larger samples should be and the patients should be followed-up for longer periods.

Keywords: COVID-19; coronavirus; surveillance; retrospective study.

DOI: https://dx.doi.org/10.4314/ahs.v21i3.19

Cite as: Dirgar E, Tosun B, Berşse S, Tosun N. Evaluating the Novel Coronavirus infection outbreak surveillance results in a state hospital: a retrospective study. Afri Health Sci. 2021;21(3). 1107-1116. bttps:/ / dx.doi.org/10.4314/ abs.v21i3.19
\end{abstract}

\section{Introduction}

In December 2019, several cases of pneumonia of unknown origin were reported in Wuhan, the capital of Hubei Province, China, and the novel coronavirus identified to cause the pneumonia was named Coronavirus Disease-19 (COVID-19) by World Health Organization (WHO) ${ }^{1}$. The disease has spread rapidly to mainland China and then to the world. WHO declared the Public Health Emergency of International Importance (PHE-

\section{Corresponding author: \\ Betül Tosun, Hasan Kalyoncu University, Airport Road, 8. km. 27000 Şahinbey / Gaziantep, Turkey ORCID: 0000-0002-4505-5887 \\ E-mail: betul.tosun@hku.edu.tr; tosunbetul@gmail.com}

IC) on January 30, 2020, and a pandemic on March 11, $2020^{2}$.

Centers for Disease Control and Prevention (CDC) (2020) have reported that the common symptoms of the disease are fever, cough, and shortness of breath and, on the other hand, the less common symptoms are weakness, myalgia, sore throat, runny nose, loss of taste and smell, diarrhea and abdominal pain. Moreover, as the number of cases has increased, the observations have shown that the first symptoms are associated not with respiratory distress, but with diarrhea, anorexia, and vomiting ${ }^{3-5}$. Computed Tomography (CT) has an important place in the diagnosis and treatment of such lung diseases; however, the radiological changes in the lungs of people with COVID-19 pneumonia have not been fully characterized. The time between the onset 
of symptoms and the development of Acute Respiratory Distress Syndrome (ARDS) is as short as 9 days among the first patients with COVID19 pneumonia; that is why early diagnosis of the disease is essential for the treatment of these patients ${ }^{6}$. Symptoms may emerge within 5-6 days after exposure to the agent; however, this period varies within the range of 2-14 days ${ }^{3,5}$. While the majority of cases recover with mild symptoms; respiratory failure, acute respiratory distress, and death may be observed in severe cases ${ }^{7}$. In particular, the disease is more severe in elderly male patients with medical comorbidities and smokers ${ }^{8}$. The virus is mostly transmitted through close contact with infected people or the droplets generated by coughing, sneezing, and speaking ${ }^{9}$. Furthermore, it is also stated that a person who comes into contact with a virus-infected surface/object can be infected in case they touch their mouth, nose, and eyes .

The management of COVID-19, for which there is no specific vaccine or antiviral treatment yet, consists of symptomatic treatment, supportive care, and isolation ${ }^{10}$. Measures should be taken to prevent the spread of the disease in fighting the outbreak. Therefore, various restrictions have been imposed in Turkey and these measures affect people's daily lives and cause economic and social problems. In this regard, the demographic data, disease symptoms, transmission route, treatment, and care results of the people with COVID-19 are of great importance for the healthcare workers in their efforts to control the outbreak and take necessary measures.

In this study, we aimed to examine the prevalence, clinical course, and outcomes of the patients with COVID-19 admitted to a state hospital in a city located in the southeastern part of Turkey.

\section{Methods}

\section{Type, Place, and Time of the Study}

This descriptive and cross-sectional study was carried out at a hospital, in Gaziantep, Turkey between March 16, 2020, and May 30, 2020 to retrospectively evaluate the results of COVID-19 surveillance.

\section{Sample of the Study}

The population of the study consisted of the patients who applied to the surveillance unit of the state hospital and were placed in inpatient isolation. The data of the study was collected by retrospectively reviewing the files of 173 patients who were diagnosed with COVID-19 within the study period and were staying in the inpatient services, intensive care units, and a student dormitory used for the patient isolation. The patients who were referred to other hospitals $(n=36)$ and whose file lacked the COVID-19 Case Information Form $(n=5)$ were excluded from this study.

\section{Data Collection Tools}

A retrospective review was carried out to collect the research data using the Covid-19 Case Information Form" in the patients' files. This form includes totally 15 questions and the following information: age, gender, whether having a chronic disease or not, unit of hospitalization, duration of hospitalization, time of the first COVID-19 symptom onset, whether there are patients with a similar clinical picture around, the history of being abroad, sample taking method and smoking status etc. In addition, the researchers followed the diagnostic test results from the patient electronic health records.

\section{Data Analysis}

The data were analyzed using International Business Machines (IBM) Statistical Package for the Social Sciences (SPSS) Statistics for Windows, Version 22.0, Armonk, NY: IBM Corp. In the descriptive statistics, mean \pm standard deviation was used in expressing the continuous numerical variables, and number (n) and percentage $(\%)$ in expressing the categorical variables. Pearson's Chi-Squared analysis was used in comparing the categorical variables and Bonferroni correction in finding which variable caused the difference. If the expected values were below 5 in $(2 \times 2)$ tables, Fisher's Exact Test was used to compare categorical data instead of Chi- Square Test. The patients' clinical outcomes were evaluated using Kaplan-Meier survival analysis. The statistical significance was set at $\mathrm{p}<0.05$.

\section{Ethical Considerations of the Study}

The study was started after receiving the required permissions from the following authorities: Faculty of Health Sciences, non-interventional Research Ethics Committee (Date: 07.05.2020, Decision No: 2020/028), The Provincial Directorate of Health, Gaziantep; the Chief Physician of Şehitkamil State Hospital, Gaziantep; and the Scientific Research Studies Unit, Directorate General for Health Services, Ministry of Health, Turkey. 


\section{Results}

The study was conducted with 173 patients diagnosed with COVID-19. Of these patients, $64.2 \%$ were male and $16.2 \%$ had a chronic disease. Their mean age was $34.76 \pm 25.75$ years. The most common chronic disease was hypertension with $9.8 \%$. Of the patients, $68.8 \%$ applied to the hospital due to the contact with a patient diagnosed with COVID-19 and 70.5\% were being followed-up in an inpatient service. Considering that it would be easy to follow-up, the asymptomatic and stable COVID-19-positive patients were followed-up in the student dormitories prepared for pandemic patients. The patients who were diagnosed with COVID-19 had a good general condition and did not show any clinical symptoms $(24.3 \%)$ were isolated and received treatment and care in a student dormitory affiliated to the hospital determined by the health directorates. Of the patients, $17.3 \%$ were smokers $(n=30)$, and $71.1 \%$ had patients diagnosed with COVID-19 around them $(n=123)$. As for the way of sample taking, combined nose and throat swabs were taken from $97.1 \%$ of the patients $(n=168)$ and tracheal swabs from $2.3 \%$ of them since they were intubated $(n=4)$. In the patients diagnoed with COVID-19, while the first samples were positive at a rate of $96.5 \%(n=167)$, this rate was found to be $22 \%(n=38)$ in the second test (Table 1).

Table 1. Patients' Descriptive information

\begin{tabular}{|c|c|c|}
\hline Characteristics & $\mathbf{n}$ & $\%$ \\
\hline \multicolumn{3}{|l|}{ Mean Age: $34.76 \pm 25.75$} \\
\hline \multicolumn{3}{|l|}{ Gender } \\
\hline Male & 111 & 64.2 \\
\hline Female & 62 & 35.8 \\
\hline \multicolumn{3}{|l|}{ Reason for Hospital Visit } \\
\hline Suspected & 54 & 31.2 \\
\hline Contact with people having COVID-19 & 119 & 68.8 \\
\hline \multicolumn{3}{|l|}{ Unit of Hospitalization } \\
\hline Service & 122 & 70.5 \\
\hline Intensive care & 9 & 5.2 \\
\hline Dormitory & 42 & 24.3 \\
\hline \multicolumn{3}{|l|}{ Chronic disease } \\
\hline Yes & 28 & 16.2 \\
\hline No & 145 & 83.6 \\
\hline Cardiovascular Disease* & 8 & 4.6 \\
\hline Chronic Obstructive Pulmonary Disease* & 7 & 4.0 \\
\hline Diabetes Mellitus* & 10 & 5.8 \\
\hline Hypertension* & 17 & 9.8 \\
\hline Cancer* & 1 & 0.6 \\
\hline Smoking status & 30 & 17.3 \\
\hline $\begin{array}{l}\text { Having patients diagnosed with COVID-19 } \\
\text { around }\end{array}$ & 123 & 71.1 \\
\hline History of Travel Abroad & 1 & 0.6 \\
\hline \multicolumn{3}{|l|}{ Way of Sample Taking } \\
\hline Combined Nose and Throat Swab & 168 & 97.1 \\
\hline Throat Swab & 1 & 0.6 \\
\hline Tracheal Swab & 4 & 2.3 \\
\hline \multicolumn{3}{|l|}{ Result of the $1^{\text {st }}$ Swab } \\
\hline Positive & 167 & 96.5 \\
\hline Negative & 6 & 3.5 \\
\hline \multicolumn{3}{|l|}{ Result of the $2^{\text {nd }}$ Swab } \\
\hline Positive & 38 & 22.0 \\
\hline Negative & 131 & 75.7 \\
\hline Not taken & 4 & 2.3 \\
\hline \multicolumn{3}{|l|}{ Clinical status outcome } \\
\hline Ongoing Hospitalization & 33 & 19.0 \\
\hline Recovered and Discharged & 138 & 79.8 \\
\hline Exitus & 2 & 1.2 \\
\hline \multicolumn{3}{|c|}{ Duration of hospitalization: Mean \pm SD: $9.43 \pm 4.51$ Median (IQR): 9 (8) } \\
\hline
\end{tabular}


When the patients' clinical symptoms at admission were analyzed, it was found that cough and fatigue $(n=67)$ were the most common clinical symptoms with $38.7 \%$, followed by headache with $23.7 \%(\mathrm{n}=41)$, respiratory distress with $18.5 \%(n=32)$, and fever with $17.9 \%$ $(n=31)$. Although $55.5 \%$ of the patients had a normal thorax CT, viral pneumonia was observed in $22.5 \%$ of them (Table 2). Of the patients, $65.3 \%$ were treated with Plaquenil tablets and used more than one medication during their hospital stay. (Table 3).

Table 2. Distribution of the patients' symptoms

\begin{tabular}{lll}
\hline COVID-19 Clinical Symptoms & n & \% \\
\hline How many days before the hospital visit did your clinical symptoms start? & \\
Mean \pm SD: $2.66 \pm 2.767$ (min:0 max:17) & 31 & 17.9 \\
Fever* & 67 & 38.7 \\
Cough* & 32 & 18.5 \\
Distress* & 28 & 16.2 \\
Throat* & 12 & 6.9 \\
History* & 67 & 38.7 \\
Fatigue* & 41 & 23.7 \\
Headache* & 11 & 6.4 \\
Loss of Taste and Smell,* & 7 & 4.0 \\
Nausea/Vomiting* & 9 & 5.2 \\
Diarrhea* & 9 & 2.9 \\
Myalgia* & 5 & 1.2 \\
Abdominal Pain* & 2 & \\
Thorax CT Result & & 55.5 \\
Normal & 96 & 12.7 \\
Icy Glass Appearance & 22 & 22.5 \\
Viral Pneumonia & 39 & 9.3 \\
Fibrotic Strips Extending to Pleura & 16 &
\end{tabular}

Table 3. Distribution of medications used by the patients.

\begin{tabular}{lll}
\hline Medications Used & n & \% \\
\hline Hydroxychlorine sulfate * & 113 & 65.3 \\
Yes & 60 & 34.7 \\
No & & \\
Enoxaparin Sodium * & 110 & 63.6 \\
Yes & 63 & 36.4 \\
No & & \\
Oseltamivire * & 37 & 21.4 \\
Yes & 136 & 78.6 \\
No & & 13.3 \\
Ceftriaxone * & 23 & 86.7 \\
Yes & 150 & 19.1 \\
No & & 80.9 \\
Moxifloxacin* & 33 & \\
No & 140 & \\
\hline
\end{tabular}

*Patients used more than one medication.

As for the patients' clinical outcome, it was found that $79.8 \%$ of the patients were discharged after recovery, $1.2 \%$ of them ( 2 patients) died, and the others' treatments were ongoing (Table 1). The survival analysis revealed that the patients' cumulative survival rate in the 1 st month was found to be $97.6 \% \pm 0.9 \%$. When the patients' recovery and discharge rates were compared by age groups, it was found that the mean discharge time for the patients under the age of 65 was $10.17 \pm 0.369$ days (at confidence interval of 95\%; lower and upper limits were 9.448 and 10.897, respectively), and the mean discharge time for the patients at the age 65 and over was $14.436 \pm 1.223$ (at confidence interval of $95 \%$; lower and upper limits were 12.039 and 16.832 , respectively); so, the patients at the age 65 and over were discharged later $(\mathrm{x} 2=9.894, \mathrm{p}=0.002)(\mathrm{Graph} 1)$. 


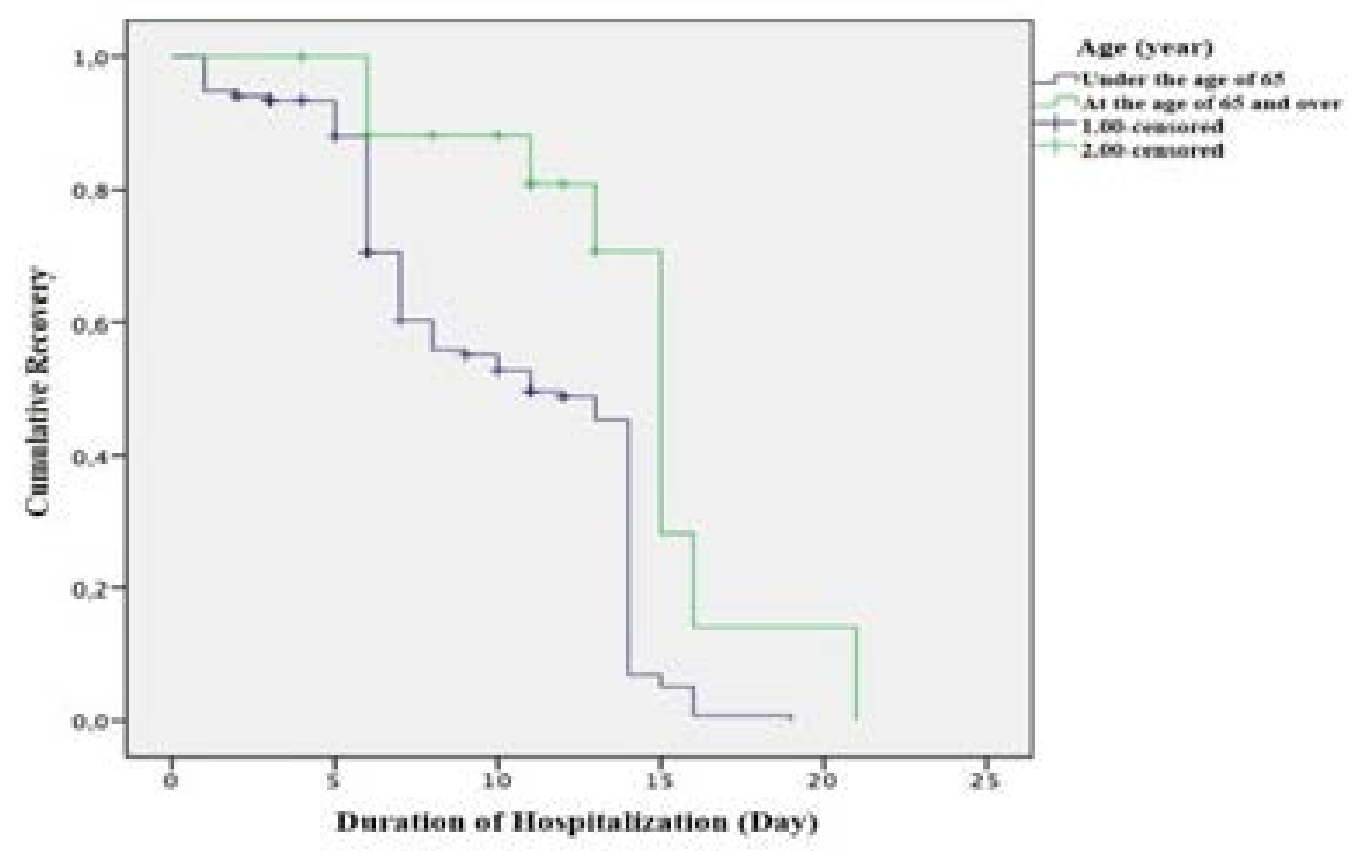

Graph 1. Comparison of the patients' recovery and discharge rates by age groups (Kaplan-Meier Curve)

When some surveillance results were compared by the age groups, it was found that the patients under the age of 65 were admitted to the hospital mostly due to contact with other people with the disease, and the patients at the age of 65 and over were treated mostly in the intensive care unit $(\mathrm{p}=0.006$ and $\mathrm{p}<0.001$, respectively). When the patients' symptoms due to COVID-19 were evaluated by the age groups, it was found that the patients at the age of 65 and over had statistically significantly more dyspnea, nausea/vomiting, and cardiovascular symptoms $(p=0.007, p=0.026$, and $p=0.038$, respectively). It was observed that the patients at the age of 65 and over had more chronic diseases; on the other hand, more patients under the age of 65 had people with similar symptoms around them and they had statistically significantly more positive symptoms in the thoracic $C T(p<0.001, p=0.004$, and $p<0.001$, respectively) (Table 4). When the patients' some surveillance results were compared by gender; it was found that the women were isolated mostly in pandemic services and the men mostly in the dormitories $(\mathrm{p}=0.033)$. It was found that while there was no statistically significant difference between the genders in terms of disease symptoms ( $p>0.05)$, more women diagnosed with COVID-19 had chronic diseases than the men $(\mathrm{p}=0.010)$ (Table 4). 
Table 4. Comparison of some surveillance data by age groups and gender $(\mathrm{n}=173)$

\begin{tabular}{|c|c|c|c|c|c|c|}
\hline & $\begin{array}{c}\text { Under the } \\
\text { age of } 65 \\
n(\%)\end{array}$ & $\begin{array}{l}65 \text { years } \\
\text { and over } \\
n(\%)\end{array}$ & $\begin{array}{c}\text { Test }\left(x^{2}\right) \\
\mathbf{p}\end{array}$ & $\begin{array}{l}\text { Male } \\
\text { n(\%) }\end{array}$ & $\begin{array}{c}\text { Female } \\
\text { n(\%) }\end{array}$ & $\begin{array}{c}\text { Test }\left(x^{2}\right) \\
\text { p }\end{array}$ \\
\hline \multicolumn{7}{|c|}{ Reason for Hospital Visit } \\
\hline Suspected & $43(27.7)$ & $11(61.1)$ & \multirow[b]{2}{*}{$0.006^{* \dagger}$} & $31(27.9)$ & $23(37.1)$ & \multirow[b]{2}{*}{$\begin{array}{c}1.558 \\
0.212 \\
\end{array}$} \\
\hline $\begin{array}{l}\text { Contact with people } \\
\text { having COVID-19 }\end{array}$ & $112(72.3)$ & $7(38.9)$ & & $80(72.1)$ & $39(62.9)$ & \\
\hline \multicolumn{7}{|l|}{ Unit of Hospitalization } \\
\hline Service $^{\mathrm{a}}$ & $108(69.7)$ & $14(77.8)$ & \multirow{3}{*}{$\begin{array}{c}16.214 \\
<0.001^{* *} \\
(\mathrm{a}-\mathrm{b}, \mathrm{c})\end{array}$} & $72(64.9)$ & $50(80.6)$ & \multirow{3}{*}{$\begin{array}{c}6.844 \\
0.033 * \\
(\mathrm{a}-\mathrm{c})\end{array}$} \\
\hline Intensive care $^{\mathrm{b}}$ & $5(3.2)$ & $4(22.2)$ & & $5(4.5)$ & $4(6.5)$ & \\
\hline Student Dormitory $^{\mathrm{c}}$ & $42(27.1)$ & $0(0)$ & & $34(30.6)$ & $8(12.9)$ & \\
\hline \multicolumn{7}{|l|}{ Fever } \\
\hline Yes & $26(16.8)$ & $5(27.8)$ & \multirow[t]{2}{*}{$0.325^{\dagger}$} & $19(17.1)$ & $12(19.4)$ & \multirow{2}{*}{$\begin{array}{l}0.135 \\
0.713 \\
\end{array}$} \\
\hline No & $129(83.2)$ & $13(72.2)$ & & $92(82.9)$ & $50(80.6)$ & \\
\hline \multicolumn{7}{|l|}{ Cough } \\
\hline Yes & $57(36.8)$ & $10(55.6)$ & \multirow[t]{2}{*}{$0.133^{\dagger}$} & $43(38.7)$ & $24(38.7)$ & \multirow{2}{*}{$\begin{array}{l}0.001 \\
0.997\end{array}$} \\
\hline No & $98(63.2)$ & $8(44.4)$ & & $68(61.3)$ & $38(61.3)$ & \\
\hline \multicolumn{7}{|l|}{ Dyspnea } \\
\hline Yes & $24(15.5)$ & $8(44.4)$ & \multirow[t]{2}{*}{$0.007 * \dagger$} & $20(18.0)$ & $12(19.4)$ & \multirow{2}{*}{$\begin{array}{l}0.047 \\
0.828 \\
\end{array}$} \\
\hline No & $131(84.5)$ & $10(55.6)$ & & $91(82.0)$ & $50(80.6)$ & \\
\hline \multicolumn{7}{|l|}{ Sore throat } \\
\hline Yes & $26(16.8)$ & $2(11.1)$ & \multirow[t]{2}{*}{$0.741^{\dagger}$} & $17(15.3)$ & $11(17.7)$ & 0.173 \\
\hline No & $129(83.2)$ & $16(88.9)$ & & $94(84.7)$ & $51(82.3)$ & 0.678 \\
\hline Headache & & & & & & \\
\hline Yes & $36(23.2)$ & $5(27.8)$ & $0.770^{\dagger}$ & $27(24.3)$ & $14(22.6)$ & 0.067 \\
\hline No & $119(76.8)$ & $13(72.2)$ & & $84(75.7)$ & $48(77.4)$ & 0.796 \\
\hline Nausea/Vomiting & & & & & & \\
\hline Yes & $4(2.6)$ & $3(16.7)$ & $0.026^{* \dagger}$ & $3(2.7)$ & $4(6.5)$ & $0.251^{\dagger}$ \\
\hline No & 151(97.4) & $15(83.3)$ & & $108(97.3)$ & $58(93.5)$ & \\
\hline Fatigue & & & & & & \\
\hline Yes & $57(36.8)$ & $10(55.6)$ & 2.397 & $43(38.7)$ & $24(38.7)$ & 0.001 \\
\hline No & $98(63.2)$ & $8(44.4)$ & 0.122 & $68(61.3)$ & $38(61.3)$ & 0.997 \\
\hline Diarrhea & & & & & & \\
\hline Yes & $7(4.5)$ & $2(11.1)$ & $0.237^{\dagger}$ & $6(5.4)$ & $3(4.8)$ & $0.871^{\dagger}$ \\
\hline No & $148(95.5)$ & $16(88.9)$ & & $105(94.6)$ & $59(95.2)$ & \\
\hline Abdominal Pain & & & & & & \\
\hline Yes & $2(1.3)$ & 0 & $1.00^{\dagger}$ & $1(0.9)$ & $1(1.6)$ & $1.00^{\dagger}$ \\
\hline No & $153(98.7)$ & $18(100)$ & & $110(99.1)$ & $98.4)$ & \\
\hline Myalgia & & & & & & \\
\hline Yes & $4(2.6)$ & $1(5.6)$ & $0.427^{\dagger}$ & $2(1.8)$ & $3(4.8)$ & $0.351^{\dagger}$ \\
\hline No & $151(97.4)$ & $17(94.4)$ & & $109(98.2)$ & $59(95.2)$ & \\
\hline Cardiovascular Sympto & & & & & & \\
\hline Yes & $5(3.2)$ & $3(16.7)$ & $0.038^{* \dagger}$ & $4(3.6)$ & $4(6.5)$ & $0.459^{\dagger}$ \\
\hline No & $150(96.8)$ & $15(83.3)$ & & $107(96.4)$ & $58(93.5)$ & \\
\hline Loss of taste and smell & & & & & & \\
\hline Yes & $9(5.8)$ & $2(11.1)$ & $0.320^{\dagger}$ & $6(5.4)$ & $58.1)$ & 0.472 \\
\hline No & $146(94.2)$ & $16(88.9)$ & & $105(94.6)$ & $57(91.9)$ & 0.492 \\
\hline Chronic disease & & & & & & \\
\hline Yes & $18(11.6)$ & $10(55.6)$ & 22.956 & $12(10.8)$ & $16(25.8)$ & 6.594 \\
\hline No & $137(88.4)$ & $8(44.4)$ & $<0.001^{* *}$ & $99(89.2)$ & $46(74.2)$ & $0.010^{*}$ \\
\hline Are there any person(s) & th similar diseas & ng around yo & & & & \\
\hline Yes & $116(74.8)$ & $7(38.9)$ & $0.004 * \dagger$ & $81(73.0)$ & $42(67.7)$ & 1.240 \\
\hline No & $38(24.5)$ & $11(61.1)$ & & $29(26.1)$ & $20(32.3)$ & 0.538 \\
\hline Is there any positive sig & Thorax CT? & & & & & \\
\hline Yes & $76(49.0)$ & $1(5.6)$ & $<0.001^{* *}$ & $54(48.6)$ & $23(37.1)$ & 2.149 \\
\hline No & $79(51.0)$ & $17(94.4)$ & & $57(51.4)$ & $39(62.9)$ & 0.143 \\
\hline Clinical status outcome & & & & & & \\
\hline Discharged & $129(83.2)$ & $9(50.0)$ & 12.374 & $91(82.0)$ & $47(75.8)$ & 2.634 \\
\hline Ongoing Treatment & $25(16.1)$ & $8(44.4)$ & $0.002 *$ & $18(16.2)$ & $15(24.2)$ & 0.268 \\
\hline Exitus & $1(0.6)$ & $1(5.6)$ & & $2(1.8)$ & 0 & \\
\hline
\end{tabular}

${ }^{*} p<0.05,{ }^{* *} p<0.001$ was accepted as statistically significant. $x^{2}=$ Pearson's Chi-squared Test, $\dagger=$ Fisher's Exact Test

\section{Discussion}

In this study, the clinical course and outcome of 173 patients diagnosed with COVID-19 were examined in a state hospital located in the southeastern part of Turkey. It was determined that the number of male patients was higher than that of female patients. Likewise, when the previous studies were reviewed, it was seen that the data results of a meta-analysis including the results of 15 observational sudies examining the distribution of COVID-19 by gender across the world have showed 
that the rate of the males infected by COVID-19 is higher than the females ${ }^{11}$. In the study carried out by Mengmeng Zhao et al., it was determined that $53.4 \%$ of 1000 patients diagnosed with COVID-19 were female ${ }^{12}$. In a study carried out by Jian Wu et al., it was revealed that $51.25 \%$ of 80 patients diagnosed with COVID-19 were female ${ }^{13}$. This varies depending on the culture and may stem from the fact that the males in the region where the hospital is located are the ones who earn a livelihood for their families, so they spend more time outside home and have contact with more people.

It is a proven finding that there is a relationship between COVID-19 and age in terms of clinical outcomes. The studies carried out across the world have revealed that as the age increases, the course of COVID-19 gets more severe $^{12}$. In the present study, the mean age of the sample was found to be 34.76 years. At the beginning of the outbreak, it was reported that the mean age for $214 \mathrm{pa}-$ tients diagnosed with COVID-19 at Wuhan Huazhong University Hospital was $52.7^{14}$. Guan et al. reported the mean age as 47 and stated that as the age increased, the rate of having a concomitant chronic disease also increased in the patient diagnosed with COVID-19 ${ }^{15}$. In the study by Zhao et al., the mean age for $1000 \mathrm{pa-}$ tients diagnosed with COVID-19 was found to be 61, and it was observed that having concomitant chronic diseases became more risker as the age increased ${ }^{12}$. Age has been the most prominent factor in the COVID-19 process. However, it is worthy of note that the rate of young population in each country is different in the studies examining the age factor.

One of the important findings was that the patients with COVID-19 had chronic diseases, especially hypertension. In other reports revealed across the world and a study involving 269,070 patients at the age of 65 and over in the UK and examining chronic diseases within the context of COVID-19, it has been asserted that the most common chronic disease in the patients with COVID-19 is hypertension, followed by coronary heart disease and diabetes. However, it was emphasized that there was no causal relationship between COVID-19 and hypertension or other chronic diseases ${ }^{16}$. Because it is noted that high prevalence of these chronic diseases in elderly people is considered normal ${ }^{16}$. The relationship between COVID-19 and chronic diseases has not been fully clarified and there is a need for further study in this regard.
One of the important findings obtained in the present study is the clinical symptoms in patients diagnosed with COVID-19. The most common symptom observed in the sample was cough and fatigue, followed by headache, respiratory distress, and fever. Likewise, according to the data of CDC and other international studies, it has been reported that patients show symptoms such as fever, cough, and shortness of breath ${ }^{17-22}$. According to the data provided by Statista, German online official statistics portal, (July-2020); the most common symptom in Italy, most severely affected country by COVID-19 in Europe, is fever, followed by shortness of breath and cough ${ }^{17}$. In the statistical analyses on the patients with COVID-19 in China, it has been observed that fever is the most common symptom with, followed by dry cough and fatigue ${ }^{18}$. Nurses should focus on symptom management in patients diagnosed with COVID-19. Symptom management; which starts with identifying the patients' symptoms, following-up the vital signs, and providing bed rest; can be considered as the first step of nursing care for patients diagnosed with COVID-19 20. In order to provide a holistic nursing care and to take a systematic approach, it is essential for nurses and all healthcare professionals to know which symptom can be at which severity and their physiopathology ${ }^{21}$. Moreover, holistically evaluating not only the common symptoms but also new or previously undiscovered or rare symptoms will ensure a smooth treatment and care for the patients.

It was found that the most common reason for contracting the disease is "having contact with other patients previously diagnosed with COVID-19". According to several reports mentioned in another study on this subject, it has been confirmed that COVID-19 transmits from person to person, and it is asserted that the disease spread by the droplets generated by coughing, sneezing, and speaking, especially in close contact [within 7 feet $(2$ meters $)]^{22}$. Therefore, nurses and patients diagnosed with COVID-19 should focus on preventing the spread of infection to other staff and patients, and strict rules should be imposed in terms of the measures to be taken ${ }^{23}$.

It was found that while the patients at the age of 65 and over were treated in intensive care units and pandemic services, the young patients were mostly isolated in student dormitories and treated in the services. The reason for this is that elderly patients had more severe symptoms due to their chronic diseases and weak im- 
mune systems, and therefore they were more dependent on others in their daily living activities; so, they were followed-up in the services and intensive care units ${ }^{5,8,21}$. Moreover, although not surprising, this was supported by the fining that the patients at the age of 65 and over in this study had more chronic diseases, respiratory distress, and cardiovascular and gastrointestinal symptoms. On the other hand, the fact that more male patients were followed-up in dormitories suggests that the disease progresses asymptomatically or with mild symptoms mostly in the male patients. Furthermore, the female patients in this study had statistically significantly more chronic diseases than the males, and this can be the reason for their being followed-up in the intensive care unit and service.

The thoracic CT diagnostic test revealed a striking finding: the patients at the age of 65 and over and the female patients are often diagnosed with COVID-19 without having any symptoms. In this study, the thorax CT results were available for all cases which were examined retrospectively. Computed tomography has been reported to be the most preferred diagnostic test in the diagnosis of COVID-19 since the symptoms such as fever, cough, fatigue, headache, and shortness of breath are not specific to the disease which can rapidly progress to a severe pneumonia and the real-time reverse transcription polymerase chain reaction (RT-PCR) test may give false negative results, although it is the gold standard in the diagnosis of COVID-19 as a powerful diagnostic test ${ }^{24-26}$. However, it has also been emphasized that CT should be used as a problem-solving method in the patients with negative RT-PCR test result rather than a screening method, especially because it contains ionizing radiation ${ }^{26,27}$. In the light of this information, the physicians, nurses, and all other healthcare professionals should take into consideration that the thoracic CT diagnostic test applied to the patients without any viral pneumonia signs will not yield the desired results. Furthermore, in this study, the fact that the COVID-19 symptoms were less observed in the thorax CT results of the male patients due to isolation in student dormitories may be put forward as an evidence that the male patients experience milder symptoms; and in the patients at the age of 65 and over, the physicians might have applied this diagnostic test not to overlook the diagnosis of COVID-19, not to confuse the symptoms with those of other diseases, and to be sure of the diagnosis.
As for the patients' clinical outcomes, it was found that most of the patients were discharged after recovery, $1.2 \%$ of them ( 2 patients) died, and the others' treatments were ongoing. The survival analysis revealed that the patients' cumulative survival rate in the 1 st month was found to be $97.6 \% \pm 0.9 \%$. As for the comparison of the patients' recovery and discharge rates by age groups, it was found that the mean discharge time for the patients under the age of 65 was about 10 days and the mean discharge time for the patients at the age 65 and over was about 15 days; so, the patients at the age 65 and over were discharged later (Graph 1). Zheng et al. (2020) reported that $12.7 \%$ of the patients died and those who died had been hospitalized for 11 days on average. The same study also reported that the mortality rate was higher in the male and elderly patients, and the mean treatment duration in the surviving patients was 22 days in those under the age of 40,34 days in those at the age of 80 and over ${ }^{28}$. It is thought that the reason why the hospital stay is prolonged with age in the patients diagnosed with COVID-19 is because their immune system is weak and they have more chronic diseases.

\section{Limitations}

This study had some limitations in that it was a single-centered retrospective study just based on the information obtained from patient records and only covered a 3-month-period for the COVID-19 positive cases.

\section{Conclusions}

In this study, it was found that the majority of the patients were male; the most common symptoms were cough, fatigue, headache, respiratory distress, and fever. It was determined that two patients $(1.2 \%)$ died, the patients under the age of 65 had a shorter hospitalization period and recovered and were discharged in a shorter time. It was found that there were differences between the age groups in terms of transmission route, the clinic where they were being followed-up, some symptoms, thorax CT result, and clinical status outcome. Moreover, the male patients were mostly followed-up in student dormitories and the female patients had more chronic diseases. In the light of all these findings, it is considered that clarifying the COVID-19 symptoms and the affecting factors will guide all healthcare personnel in the treatment and care to be designed for this disease, which took hold across the world. On the other hand, it is recommended that multi-center, prospective, generalizable, experimental or observational studies with larger 
samples be carried out and the patients be followed-up for longer periods in a way to eliminate the limitations of this study.

\section{Conflict Interest}

There is no conflict interest between the authors.

\section{References}

1. Wu F, Zhao S, Yu B, et al. A new coronavirus associated with human respiratory disease in China. $\mathrm{Na}$ ture. 2020;579(7798):265-269. doi:10.1038/s41586-0202008-3

2. World Health Organization. Events as they happen. World Health Organization. Published 2020. Accessed August 21, 2020. https://www.who.int/emergencies/ diseases/novel-coronavirus-2019/events-as-they-happen

3. CDC. Symptoms of Coronavirus. Centers for diease control and prenvetion. Published 2020. Accessed September 10, 2020. https://www.cdc.gov/coronavirus/2019-ncov/symptoms-testing/symptoms.html

4. Pan L, Mu M, Yang P, et al. Clinical characteristics of COVID-19 patients with digestive symptoms in Hubei, China: A descriptive, cross-sectional, multicenter study. Am J Gastroenterol. 2020;115(5):766-773. doi:10.14309/ ajg.0000000000000620

5. WHO. Advice on the use of masks in the context of COVID-19: interim guidance. World Health Organization. Published 2020. Accessed May 10, 2020. https:// apps.who.int/iris/handle/10665/331693

6. Shi $\mathrm{H}, \mathrm{Han} \mathrm{X}$, Jiang N, et al. Radiological findings from 81 patients with COVID-19 pneumonia in Wuhan, China: a descriptive study. Lancet Infect Dis. 2020;20(4):425434. doi:10.1016/S1473-3099(20)30086-4

7. Holshue ML, DeBolt C, Lindquist S, et al. First case of 2019 novel coronavirus in the United States. N Engl J Med. 2020;382(10):929-936. doi:10.1056/NEJMoa2001191

8. Chen N, Zhou M, Dong X, et al. Epidemiological and clinical characteristics of 99 cases of 2019 novel coronavirus pneumonia in Wuhan, China: a descriptive study. Lancet. 2020;395(10223):507-513. doi:10.1016/ S0140-6736(20)30211-7

9. CDC. How to Protect Yourself \& Others. Coronavirus Disease 2019 (COVID-19). Published 2020. Accessed September 10, 2020. https://www.cdc.gov/ coronavirus/2019-ncov/prevent-getting-sick/prevention.html

10. WHO. 14 April 2020, COVID 19 STRATEGY UPDATE.; 2020. Accessed September 10, 2020. https:// www.who.int/publications/i/item/covid-19-strategyupdate---14-april-2020

11. Ueyama H, Kuno T, Takagi H, et al. Gender Difference Is Associated With Severity of Coronavirus Disease 2019 Infection: An Insight From a Meta-Analysis. Crit Care Explor. 2020;2(6):e0148. doi:10.1097/ cce. 0000000000000148

12. Zhao M, Wang M, Zhang J, et al. Comparison of clinical characteristics and outcomes of patients with coronavirus disease 2019 at different ages. Aging (Albany NY). 2020;12(11):10070-10086. doi:10.18632/aging. 103298

13. Wu J, Liu J, Zhao X, et al. Clinical Characteristics of Imported Cases of COVID-19 in Jiangsu Province: A Multicenter Descriptive Study. Clin Infect Dis. Published online 2020. doi:10.1093/cid/ciaa199

14. Sorgun MH. Klinik Yaklașım: Nörolojik Sistem. In: Memikoğlu O, Genç V, eds. Covid-19. Ankara üniversitesi Basımevi; 2020:55-60. http://www.medicine.ankara.edu.tr/wp-content/uploads/sites/121/2020/05/ COVID-19-Kitap.pdf

15. Guan W, Ni Z, Hu Y, et al. Clinical characteristics of coronavirus disease 2019 in China. N Engl J Med. 2020;382(18):1708-1720. doi:10.1056/NEJMoa2002032

16. Schiffrin EL, Flack JM, Ito S, Muntner P, Webb RC. Hypertension and COVID-19. Am J Hypertens. 2020;33(5):373-374. doi:10.1093/ajh/hpaa057

17. Statista. Italy: common symptoms in COVID-19 deceased patients 2020. statista. Published 2020. Accessed August 14, 2020. https://www.statista.com/ statistics $/ 1110903 /$ most-common-symptoms-in-covid-19-deceased-patients-in-italy/

18. Statista. China: common symptoms of novel coronavirus patients 2020. statista. Published 2020. Accessed August 12, 2020. https://www.statista.com/ statistics/1105492/china-common-symptoms-of-coronavirus-covid-19-patients/

19. Statista. COVID-19 symptoms U.S. 2020. statista. Published 2020. Accessed August 12, 2020. https:// www.statista.com/statistics/1127573/covid-19-symptoms-us/

20. Sharma SK, Nuttall C, Kalyani V, Hemlata. Clinical nursing care guidance for management of patient with COVID-19. J Pak Med Assoc. 2020;70(5):S118-S123. doi:10.5455/JPMA.29

21. Gök Metin Z. COVID-19 Hastalığının Fizyopatolojisi ve Holistik Hemşirelik Yaklaşımı. Hacettepe Üniversitesi Hemsirelik Fakültesi Derg. 2020;7:15-24. doi:10.31125/ hunhemsire. 775658 
22. Sheikhi K, Shirzadfar H, Sheikhi M. A Review on Novel Coronavirus ( Covid-19): Symptoms, Transmission and Diagnosis Tests Research in Infectious Diseases and Tropical Medicine A Review on Novel Coronavirus ( Covid-19 ): Symptoms , Transmission and Diagnosis Tests. Res Infect Dis Trop Med. 2020;2(1):1-8. doi:10.33702/ridtm.2020.2.1.1

23. Deitrick K, Adams J, Davis J. Emergency Nursing Care of Patients with COVID-19. J Emerg Nurs. Published online 2020. doi:10.1016/j.jen.2020.07.010

24. Xie X, Zhong Z, Zhao W, Zheng C, Wang F, Liu J. Chest CT for Typical Coronavirus Disease 2019 (COVID-19) Pneumonia: Relationship to Negative RT-PCR Testing. Radiology. 2020;296(2):E41-E45. doi:10.1148/ radiol.2020200343

25. Fang Y, Zhang H, Xie J, et al. Sensitivity of Chest
CT for COVID-19: Comparison to RT-PCR. Radiology. 2020;296(2):E115-E117. doi:10.1148/radiol.2020200432

26. Özdemir M, Taydaş O, Öztürk MH. COVID-19 Enfeksiyonunda Toraks Bilgisayarlı Tomografi Bulguları. J Biotechnol Strateg Heal Res. 2020;(May). doi:10.34084/ bshr. 725584

27. Ai T, Yang Z, Hou H, et al. Correlation of Chest CT and RT-PCR Testing for Coronavirus Disease 2019 (COVID-19) in China: A Report of 1014 Cases. Radiology. 2020;296(2):E32-E40. doi:10.1148/radiol.2020200642

28. Zheng H, Tan J, Zhang X, et al. Impact of sex and age on respiratory support and length of hospital stay among 1,792 patients with COVID-19 in Wuhan, China. BrJ Anaesth. 2020;(3):2-4. doi:10.1016/j.bja.2020.07.001 